
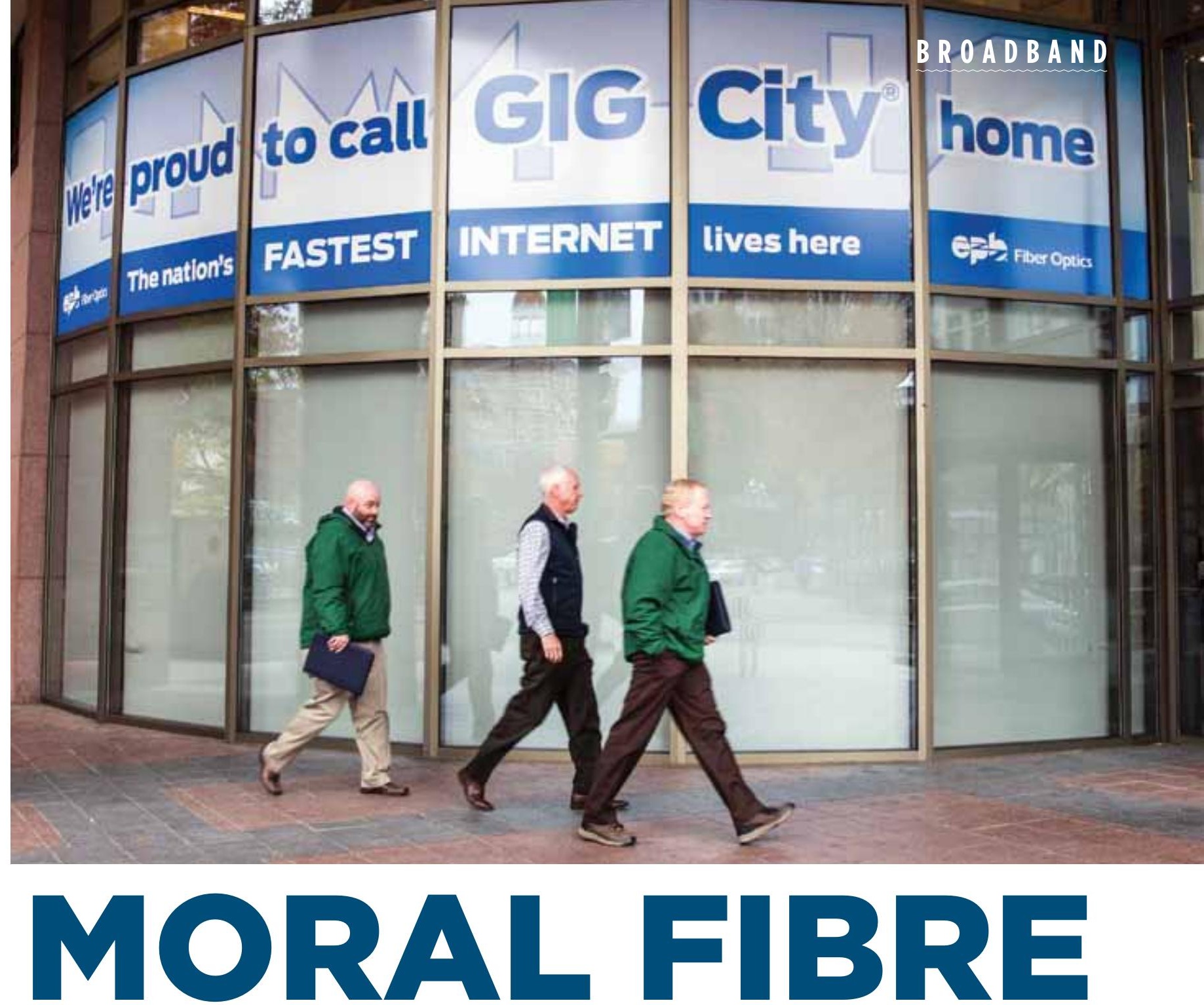

\title{
Should policymakers 'do what is right' and promote all-fibre broadband networks? CATHERINE MIDDLETON weighs up the arguments
}

T here is consensus that broadband networks are essential enablers of the digital economy, but much less consensus as to how to actually define broadband or to recognise its essential features. Without an understanding of the potential of next generation broadband networks, it is difficult to set policy agendas or shape appropriate regulatory frameworks to guide future broadband developments. This article presents a vision for next generation broadband and poses questions as to whether the technologically neutral stance that generally guides policymaking should be set aside to actively advance the deployment of fibre.

\section{DEFINING BROADBAND}

Broadband networks can be classified by speed, or described in terms of the physical network characteristics. Differentiation is made between first generation and next generation broadband, but there are differences of opinion as to whether just improving existing networks is sufficient or whether next generation broadband requires a complete transition away from copper and cable networks to all-fibre networks. There are questions too about the role of wireless networks in meeting future demand for broadband, especially as
'Gig city' is Chattanooga, Tennessee,

which claims to be the first city in the Western hemisphere to offer a $10 \mathrm{Gbps}$ fibre internet service to all residents and businesses advances are made toward the 5G standard for mobile communication, but these questions are not addressed in this article.

The language used by policymakers to describe broadband seems simple but lacks precision. For instance, the Australian government is committed to building a 'very fast' broadband network (one that makes use of a mix of first and next generation technologies), modifying earlier plans for an all-fibre 'superfast' network. The UK is also encouraging the development of 'superfast' networks (through a mix of technologies) but has just promised to bring 'fast' broadband to all. New Zealand has an all-fibre 'ultrafast' broadband initiative, while Singapore has built an 'ultra-high speed' nationwide fibre network. The European Commission's 2014 'Guide to high-speed broadband investment'1 refers to broadband delivered over fibre networks just as 'high speed' next generation broadband, but Neelie Kroes, former vice president of the European Commission, noted in 2013 that "Europe needs lightning-speed connectivity". What do these descriptors really mean?

Using speeds to define broadband does not bring clarity. The OECD recognises networks offering advertised download speeds of at least $256 \mathrm{kbps}$ 
as 'basic' broadband, but uses five additional speed tiers when measuring broadband penetration. The top tier includes advertised speeds equal to or greater than $1 \mathrm{Gbps}$ (gigabit per second, $1 \mathrm{Gbps}=$ 1,000 Mbps), about 4,000 times faster than the basic broadband tier. Across the OECD, the median advertised broadband download speed in 2013 was $30 \mathrm{Mbps},{ }^{3}$ but research shows that actual download and upload speeds are often lower than advertised speeds, especially when services are delivered over copper-based DSL (digital subscriber line) networks. ${ }^{4}$

Efforts to define broadband may be salient to policymakers, regulators and academics, but for ordinary citizens interested in getting online to access services, the terminology and technology may seem confusing, and the speed measurements complex. But broadband is now widely considered to be essential infrastructure, triggering efforts on the part of regulators and policymakers to identify future demand for broadband and to ensure everyone has access to it.

\section{ANTICIPATING THE FUTURE OF BROADBAND}

Consultations on future broadband needs, such as the European Commission's 2015 initiative, ${ }^{5}$ typically seek to identify applications and services that consumers might use in future, and ask for advice on network speeds and characteristics that will support these future demands. But these questions are difficult to answer, and more often than not predictions about future demand fail to anticipate innovative uses that are only possible as broadband network capacity increases.

Some recent articles in Intermedia provide insights on general trends influencing anticipated demand for, and supply of, broadband. Writing about regulation in the telecoms market, Brian Williamson notes that with voice telephony and basic broadband the service and the delivery technology were packaged into a single, inseparable product. ${ }^{6}$ But as the broadband ecosystem has evolved, there is, or can be, a separation between the access network (ie. a consumer's broadband network connection) and the services delivered over the access network.

As demand increases for audio, video and communication services from providers such as Skype, YouTube, Netflix and Spotify (among many others), application and service provision is becoming a global business. With consumption shifting to global service providers, broadband network operators accrue fewer revenues for services they provide over their networks. Dante Quaglione $^{7}$ and Williamson suggest that changing revenue flows will necessitate new business models, so that broadband providers can monetise the increased usage of their networks. Williamson and Peter Alexiadis ${ }^{8}$ also observe that fibre networks will replace older technologies, with the business of providing broadband access becoming more local.

While Sumit Sharma ${ }^{9}$ notes that asymmetries in technology investment cycles can bestow a technical advantage on broadband providers as they upgrade their networks, Quaglione counters that such an advantage is temporary because over time

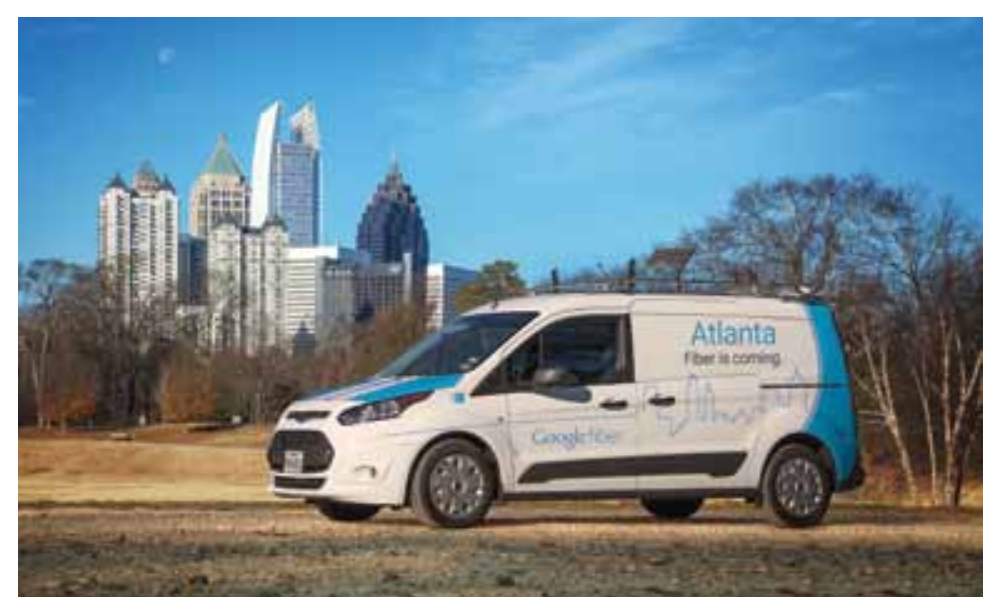

Google eyes up Atlanta, Georgia, one of the cities earmarked for its fibre service competitors will also deploy new technology and match service quality. Both Sharma and Quaglione suggest that advantage could be gained through offering differentiated services and through non-price competition. But in markets where service provision is increasingly disaggregated from broadband network provision, network operators may find it difficult to differentiate themselves from their competitors once they have all deployed the same networking technology.

Further, as Sharma notes, demand for broadband access is 'derived', meaning that it is the desire for services that are delivered over broadband networks that actually fuels demand, rather than an inherent desire for a physical broadband connection itself. It is likely then that broadband will become a commodity. The implications of these changes in the broadband market are explored below.

\section{SEPARATING CONTENT AND NETWORK PROVISION}

Despite current enthusiasm for bundled services,

there is evidence of the decline of traditional landline and television Legacy broadband businesses, as consumers frequently restrict the ability to access some applications and services. choose to cut the cord on pre-packaged services or reduce their consumption. ${ }^{10}$ Broadband providers have been acting as aggregators of services (eg. sourcing a range of 01 television programming), but while convenient, their offerings often lack flexibility and can be expensive. Consumers who want more choice in their applications and services can fulfil this desire by sourcing what they want from anywhere for delivery over their broadband links.

However, models for broadband provisioned over legacy copper or cable networks frequently involve restrictions that constrain the ability of consumers to access available applications and services. Limits of the networking technologies mean that copper (DSL) and cable (hybrid fibre coax - HFC) networks are generally designed to provide upload speeds that are lower than download speeds (a difference that is obvious when using cloud services to store, backup or share files, for instance). Offerings are often tiered by download speed, with lower capacity limits for lower speed packages. 
To manage constraints in their networks, providers charge consumers for exceeding preagreed data transfer limits, although it is possible for consumers to transfer as much data as they want by paying a premium for unlimited access. Rather than encouraging customers to use their connections freely, this approach can cause people to restrict their usage. Indeed, customers would be forgiven for thinking that many broadband providers are not particularly interested in their business, given the industry's poor reputation for customer service ${ }^{11}$ and business models that seem designed to discourage use of their services rather than encourage them.

Perhaps tempting fate, incumbent providers (those that have been offering broadband services over legacy networks) are calling for regulators to improve the availability of broadband networks by encouraging competition from new entrants that would invest in their own network infrastructure. In a market where many existing broadband providers have not treated their customers well, and where customers are simply looking for their broadband network connection to provide fast, reliable, abundant access to the multitude of applications and services available online, new entrants that just focus on providing excellent broadband connectivity and are committed to customer service will be strong competitors. In this environment, it may be wise for incumbent providers to be careful what they wish for.

\section{THE TRANSITION TO FIBRE}

When new entrants do invest in broadband infrastructure, they build fibre networks. New entrants include citizen groups building their own networks to get the service they want in their communities (eg. Broadband for Rural North, $\mathrm{B} 4 \mathrm{RN}$, in the UK, or the O-Net community network in Olds, Alberta, Canada). They include businesses deploying all-fibre networks to ensure excellent network quality for their customers and to differentiate their offerings from those of the incumbents (examples include Sonic and Ting in the US, and Hyperoptic in the UK) or to provide reliable broadband where it was not previously available (eg. the UK's Gigaclear).

Municipalities are building fibre networks to improve delivery of municipal services (eg. the fibre network in Chattanooga, Tennessee, enables its electricity smart grid and also offers broadband to everyone in the community) or specifically to provide broadband connectivity (eg. SandyNet in Sandy, Oregon, or Stokab's wholesale network in Sweden). In the US, Google is disrupting local broadband markets where it is rolling out Google Fiber, now available in Kansas City, Austin (Texas) and Provo (Utah), and design or construction is underway in another eight cities.

Each provider has its own motivation for rolling out fibre broadband. While their business models do differ somewhat, the commonalities are striking. These core characteristics of new entrants' fibre broadband offerings illustrate what the future of broadband networks can be, when they are designed to exploit the technological capacity of fibre and to meet consumer demand for network connectivity that provides reliable, high quality access to any service and application available today and in the future. The offerings are simple and guided by the principle of abundance, rather than constraint. Many new entrants offer only one or two network configurations. The standard offering provides service at the
Fibre offerings are simple and guided by the principle of abundance, rather than constraint. fastest speed possible on the network and with a symmetrical configuration (ie. equal upload and download speeds), and typically operates without any data transfer limits. In most instances today, this means that the service offers gigabit speeds (1 Gbps). Prices are reasonable, with an unlimited gigabit symmetrical service costing $£ 30$ per month from B4RN, $\$ 70$ from Google or Chattanooga's EPB, \$80 from SandyNet, and $\$ 89$ from Ting.

Recognising the necessity to upgrade legacy networks to remain competitive, cable network operators are implementing the DOCSIS3.1 standard to deliver gigabit download speeds on their existing networks. Some copper network operators are building out all-fibre networks, while others (including incumbents BT in the UK and Deutsche Telekom in Germany) are stretching the life of existing assets by investing in technologies such as vectoring that allow faster speeds over copper networks. While these investments will allow incumbents to compete on network speed in the short to medium term, their existing business models (featuring complex pricing structures and relying on bundled services as a means of differentiation) may not serve them well in an environment where broadband is simply the infrastructure that provides access to online applications and services.

\section{BROADBAND AS A COMMODITY}

A look at other essential infrastructure helps to illustrate this point. These have evolved over time, but in the developed world using electricity or water today is a simple matter. Turn on a tap and water is available. Plug in an appliance and the electrical system provides power to it. These systems are highly reliable, and service is easy to obtain. Customers do not have to choose whether they want regular or super or ultra variants of electricity or water services. Electricity is simply electricity and water is simply water.

The systems are engineered for scalability, can support new uses, and upgrades do not typically require changes to the ways that people engage with the services. As broadband becomes more essential to the economy and everyday life, shouldn't expectations for ease of use and availability be the same as those for water or electricity? If so, it seems that simple, unconstrained, upgradable models for broadband provision will be the preferred choice in future. 


\section{BROADBAND: THE NEXT GENERATION}

My discussion above offers insights into anticipated changes in the broadband market, but uncertainties do remain about how the future for broadband networks will evolve. Some observers suggest that gigabit speeds are not yet warranted and that technological advances may allow wireless networks to meet the needs of many consumers, thereby reducing demand for fixed line broadband. ${ }^{12}$ It is noted that current usage patterns (especially given the dominance of video downloads in network traffic today) do not require symmetrical networks and that there is limited demand for the fastest services offered by fibre network providers. But despite these uncertainties, rather than reinforcing an environment in which the dominant model has been to impose limits, convince citizens that higher capacity networks are not yet necessary, ${ }^{13}$ and generally deny the possibilities of unfettered access, why not challenge regulators and policymakers to encourage the supply of broadband networks in ways that can foster innovation and enable future prosperity?

To do so will require a shift away from thinking about broadband in terms of minimum acceptable speeds in favour of recognising the importance of building capacity for the future. Operators who argue that there is not yet a business case to roll out future-proof networks should consider what is motivating the companies, communities and local and national governments that are building their own fibre. There are viable models, today, for fibre to the home service, models in which the primary business is network provision and the product on offer is a fast, symmetrical and unlimited connection to the online world.

While incumbent operators are resisting regulatory efforts that would require them to allow other providers to deliver services over their newly built fibre networks, other companies (eg. CityFibre in the UK) are building their businesses by recognising the value of encouraging more traffic onto their networks as a means of increasing revenue. Incumbent operators argue that mandating access to their fibre networks will reduce their incentives to invest in new infrastructure. Rather than offering wholesale access to competitors, incumbents state that they would have a stronger incentive to invest if their competitors built their own networks.

But as the value for the consumer is in access to a wide array of services and applications from a multitude of providers, rather than in the network itself, the principle that competition and choice arise through the deployment of multiple physical networks loses its currency. As all network providers must find ways to monetise traffic flows over their networks, encouraging a proliferation of networks over which traffic flows are distributed may not be an optimal approach.

The transition away from constrained legacy broadband to a new future-proof environment offering abundant, simple, reliable connectivity will take time. Legacy broadband services were deployed on networks that were already physically connected

\section{A single fibre network can be deployed in a region and opened to any party interested in providing a service over it.}

to consumer premises, whereas extending fibre everywhere requires extensive new construction. There are many fibre deployments underway or in the planning stages, but most are serving discrete local areas (the exceptions are national broadband network deployments, such as in New Zealand and Singapore, and large-scale deployments from incumbent operators, which to date are more likely to be announced than actually underway).

Today, the vast majority of broadband connections in OECD countries are provided by incumbent operators using legacy broadband networks. ${ }^{14}$ Unless or until they are challenged by competitors, the incumbents will be slow to invest in network upgrades. Nevertheless, the shift toward acquiring applications and services from global providers coupled with the emergence of viable business models to provide reliable, high quality abundant access over commodity fibre networks will define the next generation of broadband connectivity. The next generation will be both technically and commercially distinct from the legacy first generation initially deployed in the late 1990s.

Market developments to date demonstrate that there are business cases to build fibre networks in many locations, with providers choosing to open their networks to competitors to increase their revenues from network operations. However, as deployments are often on a local level, it would be beneficial for policymakers to consider strategies to ensure universal access to next generation broadband. As was the case with legacy broadband, a key challenge will be to determine how to extend service to areas where no providers are willing to invest. Rather than trying to encourage competing providers to roll out infrastructure though, a single fibre network can be deployed in a region and opened to any party interested in providing a service over it.

Although policymakers and regulators have been promoting the development of competing facilities to advance next generation broadband deployments, approaches that encourage co-investment may be more appropriate if the network itself is a commodity. Technological neutrality discourages policy approaches that favour one technology over another. But given the importance of ensuring high quality broadband is rolled out across entire nations, should consideration be given to explicitly encouraging the shift from legacy to fibre networks? Should policymakers abandon efforts to define minimum acceptable speeds for next generation broadband, in favour of encouraging models that simply offer the fastest possible speeds and allow access to the full capacity of fibre networks? Is it time for a change in thinking about how broadband is conceptualised to move from the constraints of first generation broadband to a model of abundance now possible with wide deployment of all-fibre networks?

CATHERINE MIDDLETON is Canada Research Chair in Communication

Technologies in the Information Society at the Ted Rogers School of

Management, Ryerson University, Canada.

REFERENCES 1 European Commission (2014). Guide to high-speed broadband investment, release 1.1. bit.ly/1MlaQf1 2 European Commission (2013). 100\% basic broadband coverage achieved across Europe - EU target achieved ahead of schedule. Next stop is fast broadband for all. Press release, 17 0ctober 2013. bit.ly/10CVdwm 3 OECD (2015). OECD Digital economy outlook 2015. Paris: OECD Publishing. 4 European Commission (2014). Quality of broadband services in the EU. bit.ly/IMlaZPp $\mathbf{5}$ European Commission (2015). Public consultation on the needs for internet speed and quality beyond 2020. bit.ly/XXKzHL 6 Williamson B (2015). A tipping point for regulation. Intermedia 43 (3): 12-15. 7 Quaglione D (2014). Wanted: A new competition paradigm. Intermedia 42 (4/5): 42-46. 8 Alexiadis P (2015). Europe in the round. Intermedia 43 (3): 34-38. 9 Sharma S (2015). Taming the oligopolists. Intermedia 43 (2): 11-14. 10 See: Australian Communications and Media Authority (2013-2014). Communications report; (anadian Radio-Television and Telecommunications Commission (2015). Communications monitoring report; Ofcom (2015). Communications market report. 11 American Customer Satisfaction Index (2015). ACSI Telecommunications and information report 2015. 12 Layton R (2015). Testing telecoms assumptions. Intermedia 43 (1): 25-28. 13 As with Australia's redesigned National Broadband Network. 14 OECD (2015). Fixed and wireless broadband subscriptions by technology. bit.ly/licP4RGV 